\title{
Economics of post harvest losses in onion in Jhunjhunu district of Rajasthan
}

SWATI SHARMA AND RUCHIRA SHUKLA

Received : 04.01.2017; Revised : 03.03.2017; Accepted : 17.03.2017

\begin{abstract}
A study was undertaken to examine the nature and extent of post-harvest losses in onion supply chain in the Jhunjhunu district which is major onion district of Rajasthan. A total sample size of 75 onion growers, 20 wholesalers and 25 retailers were taken from Jhunjhunu district. Maximum aggregate post-harvest losses $(23.62 \mathrm{~kg} / \mathrm{q})$ have been found at producer level due to faulty storage, lack of adequate transportation, drying, improper handling of the produce at the time of marketing, rotted bulbs, doubles, bolters, poor packing facilities, injury at the time of harvesting and de-topping. Total losses in the supply chain were estimated to be $29.02 \mathrm{~kg} / \mathrm{q}(81.39 \%)$ losses were observed at farm level and rest were contributed at wholesale and retail level. The farm level post harvest losses excluding the losses at farm level storage for Jhunjhunu district was estimated to be $26676.96 \mathrm{q}$ for the year 2009-10.
\end{abstract}

KEY WORDS : Post-harvest losses, Onion

How to cite this paper : Sharma, Swati and Shukla, Ruchira (2017). Economics of post harvest losses in onion in Jhunjhunu district of Rajasthan. Internat. J. Com. \& Bus. Manage, 10(1) : 15-19, DOI: 10.15740/HAS/IJCBM/10.1/15-19.

Email: swatisharma_abm@yahoo.co.in 